the Otago Exercise Program for 80 and older, \$570 for Tai Chi and $\$ 311$ for Stepping On. The net present values (NPVs) were \$354 for Tai Chi, \$276 for the Otago Exercise Program for 80 years and older and $\$ 156$ for Stepping On. The Otago Exercise Program for 65 and older showed a negative NPV. The Tai Chi program at $\$ 1.6$ per dollar invested (160\% return) had the higher ROI followed by Stepping On at $\$ 1$ per dollar invested (100\% return) and the Otago Exercise Program for persons 80 and older at $\$ 0.7$ per dollar invested (70\% return). The magnitudes of the ROIs for the above interventions indicate excellent financial performances when compared to the $12 \%$ historical return of the U.S. Standard and Poors 500 index.

\title{
0886 THE BUSINESS CASE FOR INTERVENTIONS TO PREVENT FALL INJURIES IN OLDER ADULTS
}

VGCarande-Kulis*, J Stevens, B L Beattie, I Arias Correspondence:Centers for Disease Control and Prevention (CDC), 1600 Clifton Rd NE MS D72, Atlanta, GA 30333 USA

\subsection{6/ip.2010.029215.886}

A business case for programs to prevent falls in older adults was conducted by the U.S. CDC National Centers for Injury Prevention and Control (NCIPC) and the National Council on Aging (NCOA). Interventions studied were as follows: the Otago Exercise Program delivered to (a) persons aged 65 and older and (b) persons aged 80 and older, the Tai Chi: Moving for Better Balance program, and the Stepping On program. The average intervention costs were $\$ 415$ for both age-groups of the Otago Exercise Program, \$216 for Tai Chi and \$155 for Stepping On. Benefits in averted direct medical costs were $\$ 363$ for the Otago Exercise Program for 65 and older, \$691 for 